\title{
Treatment of gonadotropin dependent precocious puberty due to hypothalamic hamartoma with gonadotropin releasing hormone agonist depot
}

Vinicius N de Brito, Ana C Latronico, Ivo J P Arnhold, Leonard S S Lo,

Sorahia Domenice, Maria C C Albano, Maria C B V Fragoso, Berenice B Mendonca

\begin{abstract}
The gonadotropin releasing hormone (GnRH) secreting hypothalamic hamartoma $(\mathbf{H H})$ is a congenital malformation consisting of a heterotopic mass of nervous tissue that contains GnRH neurosecretory neurons attached to the tuber cinereum or the floor of the third ventricle. HH is a well recognised cause of gonadotropin dependent precocious puberty (GDPP). Long term data are presented on eight children (five boys and three girls) with GDPP due to HH. Physical signs of puberty were observed before 2 years of age in all patients. At presentation with sexual precocity, the mean height standard deviation (SD) for chronological age was $+1.60(1.27)$ and the mean height SD for bone age was $-0.92(1.77)$. Neurological symptoms were absent at presentation and follow up. The hamartoma diameter ranged from 5 to $18 \mathrm{~mm}$ and did not change in six patients who had magnetic resonance imaging follow up. All patients were treated clinically with GnRH agonists (GnRH-a). The duration of treatment varied from 2.66 to 8.41 years. Seven of the eight children had satisfactory responses to treatment, shown by regression of pubertal signs, suppression of hormonal levels, and improvement of height SD for bone age and predicted height. One patient had a severe local reaction to GnRH-a with failure of hormonal suppression and progression of pubertal signs. It seems that $\mathrm{HH}$ is benign and that GnRH-a treatment provides satisfactory and safe control for most children with GDPP due to HH.

(Arch Dis Child 1999;80:231-234)
\end{abstract}

Keywords: hypothalamic hamartoma; gonadotropin releasing hormone agonist; precocious puberty

Gonadotropin dependent precocious puberty (GDPP) occurs as a result of premature pituitary stimulation and increased secretion of gonadotropins. The advent of magnetic resonance imaging (MRI) has made the diagnosis of central nervous system lesions more precise and accurate. Gonadotropin releasing hormone $(\mathrm{GnRH})$ secreting hypothalamic hamartoma $(\mathrm{HH})$ is the most common known cause of GDPP. It is a benign congenital malformation of the brain consisting of a heterotopic mass of nervous tissue that contains $\mathrm{GnRH}$ neurosecretory neurones. $\mathrm{HH}$ is usually situated in the posterior hypothalamus between the tuber cinereum and mamilliary bodies or on the floor of the third ventricle. ${ }^{12}$

The goal of treatment in GDPP is to ensure the regression or arrest of secondary sexual characteristics and of skeletal maturation to preserve genetic height potential. Treatment with GnRH agonists (GnRH-a) induces downregulation of luteinising hormone $(\mathrm{LH})$ and follicle stimulating hormone (FSH) secretion, thereby suppressing the hypothalamic pituitary gonadal axis. $^{3}$

Current data support the effectiveness and safety of GnRH-a treatment for GDPP, whether of the idiopathic type or secondary to $\mathrm{HH} .{ }^{1}$ Side effects are reported rarely. ${ }^{4-6}$

We present long term clinical, radiological, and therapeutic data for eight children with GDPP due to HH.

Patients and methods

Eight patients with $\mathrm{HH}$ (five boys and three girls) had onset of pubertal signs between birth
$\mathrm{V} N$ de Brito

I J P Arnhold

$S$ Domenice

M C C Albano

M C B V Fragoso

B B Mendonca

Radiology

Department, Hospital

das Clinicas, São

Paulo University

Medical School, Brazil

L S S Lo

Correspondence to:

Dr B B Mendonca, Hospital

das Clinicas, Disciplina de

Endocrinologia, Caixa Postal

3671, 01060-970, São

Paulo-SP, Brazil.

Accepted 24 September 1998
Table 1 Effects of GnRH-a treatment on clinical features, height standard deviation (SD) for chronological age, and height SD for bone age in GDPP due to hypothalamic hamartoma

\begin{tabular}{|c|c|c|c|c|c|c|c|c|}
\hline \multirow[b]{2}{*}{ Patient } & \multirow{2}{*}{$\begin{array}{l}\text { CA at onset of } \\
\text { GnRH-a } \\
\text { treatment (years) }\end{array}$} & \multirow{2}{*}{$\begin{array}{l}\text { Age at } \\
\text { treatment } \\
\text { (years) }\end{array}$} & \multicolumn{3}{|l|}{ Baseline } & \multicolumn{3}{|c|}{ Latest visit } \\
\hline & & & $\begin{array}{l}\text { Tanner } \\
\text { stage }\end{array}$ & $\begin{array}{l}\text { Height } S D \\
\text { for } C A\end{array}$ & $\begin{array}{l}\text { Height } S D \\
\text { for } B A\end{array}$ & $\begin{array}{l}\text { Tanner } \\
\text { Stage }\end{array}$ & $\begin{array}{l}\text { Height } S D \\
\text { for } C A\end{array}$ & $\begin{array}{l}\text { Height } S D \\
\text { for } B A\end{array}$ \\
\hline 1 & 1.33 & 8.4 & G2PH1 & +0.21 & +1.46 & G1PH1 & -0.47 & +1.37 \\
\hline 2 & 1.91 & 3.4 & G2PH3 & +2.90 & -1.32 & G1PH2 & +2.24 & +0.60 \\
\hline 3 & 2.16 & 2.8 & G2PH1 & +0.20 & +0.20 & G1PH1 & +1.09 & +0.68 \\
\hline 4 & 1.16 & 3.6 & $\mathrm{G} 2 \mathrm{PH} 2$ & +2.81 & +0.16 & G1PH1 & +3.05 & +1.59 \\
\hline $5^{\star}$ & 2.5 & 5.0 & - & - & - & G4PH4 & +5.87 & -0.51 \\
\hline 6 & 1.33 & 6.9 & B3PH1 & +1.04 & -0.66 & B3PH1 & +3.11 & +0.02 \\
\hline 7 & 1.83 & 4.1 & B4PH3 & +3.0 & -3.71 & В3PH3 & +3.52 & +0.46 \\
\hline 8 & 1.08 & 2.7 & $\mathrm{~B} 2 \mathrm{PH} 1$ & +1.04 & -2.60 & $\mathrm{~B} 1 \mathrm{PH} 1$ & +0.33 & +3.10 \\
\hline Mean (SD) & $1.66(0.51)$ & $4.61(2.05)$ & & $+1.60(1.27)$ & $-0.92(1.77)$ & & $+1.83(1.54)$ & $+1.11(1.02)$ \\
\hline Range & 1.08 to 2.5 & 2.66 to 8.41 & & 0.2 to 3.0 & -3.71 to 1.46 & & -0.47 to 3.52 & 0.02 to 3.10 \\
\hline
\end{tabular}

${ }^{\star}$ Case 5 was not included in the statistical analysis; $\mathrm{p}<0.05$ (baseline height SD for bone age $v$ latest height SD for bone age). $\mathrm{CA}$, chronological age; BA, bone age; B, breast; PH, pubic hair; G, genitalia (testicular size), according to Tanner's criteria. 
Table 2 Peak GnRH stimulated concentrations of gonadotropin and sexual steroids in eight children with GDPP due to $\mathrm{HH}$ before and during treatment with $\mathrm{G} n \mathrm{RH}-\mathrm{a}$

\begin{tabular}{|c|c|c|c|c|c|c|c|c|c|}
\hline \multirow[b]{2}{*}{ Patient } & \multirow[b]{2}{*}{$\operatorname{Sex}$} & \multicolumn{2}{|c|}{ Peak $L H(I U / L)$} & \multicolumn{2}{|c|}{ Peak FSH (IU/L) } & \multicolumn{2}{|c|}{ Testosterone (ng/dl) } & \multicolumn{2}{|c|}{ Oestradiol (pg/ml) } \\
\hline & & Baseline & $\begin{array}{l}1 \text { year after } \\
\text { treatment }\end{array}$ & Baseline & $\begin{array}{l}1 \text { year after } \\
\text { treatment }\end{array}$ & Baseline & $\begin{array}{l}1 \text { year after } \\
\text { treatment }\end{array}$ & Baseline & $\begin{array}{l}1 \text { year after } \\
\text { treatment }\end{array}$ \\
\hline 1 & M & $36^{\star}$ & 1.7 & $18^{\star}$ & $<1$ & $213^{\star}$ & $<10^{\star}$ & & \\
\hline 2 & M & 77 & 1.0 & 22 & $<1$ & $275^{\star}$ & $23^{\star}$ & & \\
\hline 3 & M & 13 & 0.9 & 4 & $<1$ & $34^{\star}$ & $22^{\star}$ & & \\
\hline 4 & M & 13 & 1.6 & 2 & $<1$ & $241^{\star}$ & $23^{\star}$ & & \\
\hline 5 & M & $37^{\star}$ & 23 & $13^{\star}$ & 11 & $251^{\star}$ & $565^{\star}$ & & \\
\hline 6 & $\mathrm{~F}$ & $52^{\star}$ & 1.5 & $9^{\star}$ & $<1$ & & & $<10^{\star}$ & $<6.8$ \\
\hline 7 & $\mathrm{~F}$ & 23 & 1.5 & 8 & $<1$ & & & $15^{\star}$ & $<6.8$ \\
\hline 8 & $\mathrm{~F}$ & 23 & 1.0 & 13 & $<1$ & & & 11 & $<6.8$ \\
\hline
\end{tabular}

^Radioimmunoassay.

Normal pubertal response LH peak after $100 \mu \mathrm{g}$ of GnRH: for girls, >15 IU/1 radioimmunoassay, > 7.0 IU/L immunofluorometric assay; for boys, > 25.5 IU/1 radioimmunoassay , > $8.4 \mathrm{IU} / 1$ immunofluoremetric assay.

Testosterone (ng/dl): prepubertal levels $<30 \mathrm{ng} / \mathrm{dl}$ (radioimmunoassay).

and 2 years of age. Pubertal development was evaluated according to Tanner's criteria. $^{78}$ Table 1 presents clinical features of these patients. No intellectual impairment, seizures, or behavioural disturbances were observed.

The GnRH stimulation test was done by administering $100 \mu \mathrm{g}$ of intravenous $\mathrm{GnRH}$ (HRF, Wyeth-Ayerst; Maidenhead, Berkshire, UK) with blood samples for gonadotropin measurements obtained before and 15, 30, 45, and 60 minutes after injection. Plasma $\mathrm{LH}$ and $\mathrm{FSH}$, testosterone, oestradiol, and dehydroxyepiandrosterone sulphate (DHEA-S) were measured by radioimmunoassay or immunofluorometric assay. We considered the response as pubertal when peak LH concentrations were $>7.0 \mathrm{IU} / 1$ for girls and $>8.4 \mathrm{IU} /$ 1 for boys when measured by immunofluorometry, and peak LH > $15 \mathrm{IU} / 1$ for girls and $>25.5 \mathrm{IU} / 1$ for boys when measured by radioimmunoassay. ${ }^{39}$ The test was repeated every six months during treatmentimmediately before a new GnRH-a administration for monitoring GnRH-a treatment. Adequate suppression during treatment was accepted if the peak values after $\mathrm{GnRH}$ were $<1.7 \mathrm{IU} / 1$ for $\mathrm{LH}$ and $2.5 \mathrm{IU} / 1$ for $\mathrm{FSH}$ according to Parker et al. ${ }^{10}$ Bone age was determined according to Greulich and Pyle. ${ }^{11}$ The neuroradiological assessment was done in all patients using MRI interpreted by the same radiologist (LSSL). All patients were treated with a GnRH-a, either goserelin $(3.6 \mathrm{mg}$ intramuscularly) or leuprolide acetate (3.75 mg subcutaneously), every four weeks.

\section{STATISTICAL ANALYSIS}

Comparison between height standard deviation (SD) for bone age at onset of treatment and the latest evaluation was analysed by Friedman test.

\section{Results}

The main problems in girls were premature breast development and menarche, whereas in boys they were pubic hair development, increased testicular size, and penile enlargement. Treatment with GnRH-a arrested or involuted sexual characteristics in seven of the eight patients. The hamartoma was attached in proximity to the tuber cinereum and mamilliary bodies and extended into the suprasellar cistern in all patients.
Hamartomas ranged in diameter from 5-18 $\mathrm{mm}$. All patients had sessile masses. The duration of follow up with neuroimaging was 4-6 years in six patients. Neither the size nor the shape of the harmatoma changed over time in these patients.

All children had an initial pubertal response after their $\mathrm{GnRH}$ test (table 2). Treatment with GnRH-a suppressed basal and peak LH and FSH concentrations after GnRH administration in seven of eight patients.

The mean height SD for chronological age was $+1.6(1.27)$ at baseline and $1.83(1.54)$ at the latest visit. The mean height SD for bone age increased significantly from -0.92 (1.77) to $1.11(1.02)(\mathrm{p}<0.05)$ during GnRH treatment (table 1).

Six patients were treated with $\mathrm{GnRH}$-a every four weeks with a good response. The treatment of patient 6 was changed to GnRH-a every three weeks because he presented with partial failure of hormone suppression and pubertal progression on standard treatment, with later arrest of pubertal signs.

One patient (case 5) presented with a severe local reaction at the injection site, resulting in induration and erythema followed by sterile abscess formation and treatment failure, which was characterised by progression of pubertal signs and bone age and nonsuppressed testosterone and gonadotropin concentrations. $\mathrm{He}$ had been treated previously elsewhere with three different GnRH-a (leuprolide acetate, goserelin, and tryptorelin) over approximately four years with short acting and depot presentations and different forms of administration (daily, monthly) with poor outcome. When first seen in our clinic he was 7 years old with a bone age of 14 years and Tanner pubertal stage V. Testosterone concentrations and GnRH stimulated $\mathrm{LH}$ concentrations were high. $\mathrm{He}$ presented with local induration at the injection sites characterised by atrophy of subcutaneous tissue and nodule formation. We used another GnRH-a (goserelin) together with an antihistamine every four weeks for three months, but he again developed local induration with failure of hormone suppression, and has been treated subsequently with cyproterone acetate $75 \mathrm{mg} / \mathrm{m}^{2}$. 


\section{Discussion}

Hypothalamic and adjacent lesions are well described causes of precocious puberty and include hamartomas, gliomas, ectopic pinealomas, craniopharyngiomas, neurofibromas, tuberculous meningitis, suprasellar arachnoid cysts, and basilar artery aneurysms. Hypothalamic hamartomas are one of the most frequently cited causes of GDPP. ${ }^{12}$

The $\mathrm{HH}$ functions as an ectopic $\mathrm{GnRH}$ pulse generator that escapes the intrinsic central nervous system inhibitory mechanism which restrains the onset of puberty during the juvenile pause, thus resulting in GDPP. ${ }^{1}$ Patients with $\mathrm{HH}$ have physical signs of puberty indistinguishable from those with idiopathic GDPP. ${ }^{13}$

The diagnosis of GDPP due to $\mathrm{HH}$ is suggested by early onset of sexual precocity, generally before 2 years of age, especially if associated with gelastic seizures without focal neurological signs, in the presence of an isodense hypothalamic mass, seen on neuroimaging.

MRI is the imaging method of choice in the diagnosis of GDPP. The interpeduncular mass is well defined on computed tomography, but fine slices (2-3 mm width) in both axial and coronal planes should be used. The appearances on MRI are similar. The advantages of MRI over computed tomography are the avoidance of ionising radiation and iodine contrast medium and the possibility of obtaining clear visualisation in the sagittal as well as coronal and axial planes. The persistent grey matter intensity of the lesion in $\mathrm{T} 1$ and $\mathrm{T} 2$ weighted images indicated the homogeneous, neuronal nature of the masses. ${ }^{12}$ The most common presentation of $\mathrm{HH}$ was a small and well defined mass in the inferior side of the hypothalamus, showing isointensity on T1 weighted images and hyperintensity on T2 weighted images compared with the grey matter. $^{2}$

MRI identified central nervous system lesions in 12 of 70 children with GDPP referred to the developmental endocrinology unit at the University of São Paulo medical school. Apart from the eight patients with $\mathrm{HH}$ reported here, two patients had arachnoid cysts, one meningomyelocele, and one neurofibromatosis with cerebellar glioma.

Long term GnRH-a treatment was satisfactory in seven cases. All patients presented arrest or regression of secondary sexual characteristics, significant improvement of the mean SD height for bone age (table 1) and hormonal level suppression, as shown by basal and $\mathrm{GnRH}$ stimulated concentrations of $\mathrm{LH}$ at prepubertal levels (table 2). One boy presented with a local reaction followed by failure of hormonal suppression with progression of pubertal signs. The severe local reaction developed at the site of depot $\mathrm{GnRH}-\mathrm{a}$ injection, followed by obvious escape from the intended gonadotropin suppression. The most likely cause of the local reaction is the biodegradable microcapsules made from a copolymer of lactic and glycolic acids (the "vehicle"). In these situations, investigators have increased the dosage in the hope that more drug will be absorbed, or the dose frequency is altered to every three weeks, although data do not exist to substantiate the efficacy of either strategy. ${ }^{14-16}$

The incidence of all types of clinically evident reactions to the depot $\mathrm{GnRH}-\mathrm{a}$ injections is somewhat difficult to ascertain. Manasco et al cited 3-8\% of children with local reactions. ${ }^{13}$ We have treated 70 patients with GDPP, using two long acting GnRH-a (leuprolide acetate or goserelin), and observed local reactions in one girl characterised by hyperaemia, and a severe local reaction in one boy.

In our study, none of the patients presented with neurological disorders. The hamartoma diameter of our patients ranged from 5-18 mm. Mahachoklertwattana et al reviewed the relation between the size of the $\mathrm{HH}$ and the occurrence of seizures, ${ }^{1}$ demonstrating that no patients with a hamartoma diameter of less than $10 \mathrm{~mm}$ had seizures; in contrast, all patients with a hamartoma of $25 \mathrm{~mm}$ or larger had seizures.

Late MRI evaluation in six of our cases showed stability of lesions in shape, size, and signal intensity. Surgical intervention in $\mathrm{HH}$ may be necessary in the rare instance of mass enlargement or compression of adjacent tissues causing progressive neurological deficit, hydrocephalus, or intractable seizures. ${ }^{161317}$ A recent report concluded that total resection of an $\mathrm{HH}$ is the only surgical procedure that has a significant chance of reversing precocious puberty, and for pedunculated $\mathrm{HH}$, total removal can be accomplished safely. Prolonged follow up of the two patients who underwent surgery showed that puberty reversal had not been complete, and permanent cure of the GDPP had not been achieved. The authors recommended that the initial management for a child with GDPP due to $\mathrm{HH}$, even when it is pedunculated, should be clinical treatment with GnRH-a. ${ }^{18}$

We conclude that $\mathrm{HH}$ was the most frequent known cause of GDPP in our series, behaved benignly, and that GnRH-a treatment provided satisfactory and safe control of precocious pubertal development.

1 Mahachoklertwattana P, Kaplan SL, Grumbach MM. The luteinizing hormone-releasing hormone-secreting hypothalamic hamartoma is a congenital malformation: natural history. f Clin Endocrinol Metab 1993;77:118-24.

2 Lona Soto A, Takashi M, Yamashita Y, Sakamoto Y, Shinzato J, Yoshizumi K. MRI findings of hypothalamic hamartoma: report of five cases and review of the literature. Comput Med Imaging Graph 1991;15:415-21.

3 Lee P. Laboratory monitoring of children with precocious puberty. Arch Pediatr Adolesc Med 1994;148:369-76.

4 Pescovitz OH, Comite F, Hench K, et al. The NIH experience with precocious puberty: diagnostic subgroups and response to short-term luteinizing hormone releasing hormone analogue therapy. F Pediatr 1986;108:47-54

5 Lee PA, Page JG. Effects of leuprolide in treatment of central precocious puberty. F Pediatr 1989;114:321-4.

6 Starceski PJ, Lee PA, Albright AL, Migeon CJ. Hypothalamic hamartomas and sexual precocity: evaluation of treatment options. Am $\mathcal{F}$ Dis Child 1990;144:225-8.

7 Marshall WA, Tanner JM. Variations in pattern of pubertal changes in girls. Arch Dis Child 1969;44:291-303.

8 Marshall WA, Tanner JM. Variations in pattern of pubertal changes in boys. Arch Dis Child 1970;45:13-23. 
9 Mendonca BB, Borges MF, Batista MC, et al. Comparação entre método imunofluorimétrico (FIA) e radioimunometrico (RIA) na determinação de valores de gonadotrofinas basais e apos GnRH em crianças pré-puberais norBras $1992 ; 36: 28$

10 Parker, KL, Baens-Bailon, RG, Lee, PA. Depot leuprolide acetate dosage for sexual precocity. F Clin Endocrinol Metab 1991;73:50-2.

11 Greulich W, Pyle S. Radiologic atlas of hand and wrist. Stanford: Stanford University Press, 1959.

12 Beningfield SJ, Bonnici F, Cremin BJ. Case reports. Magnetic resonance imaging of hypothalamic hamartomas. Br Э Radiol 1988;61:1177-80.

13 Valdueza JM, Cristante L, Dammann O, et al. Hypothalamic hamartomas: with special reference to gelastic epilepsy and surgery. Neurosurgery 1994;34:949-58.
14 Neely EK, Hintz RL, Parker B, et al. Two-year results of treatment with depot leuprolide acetate for central precocious puberty. $\mathcal{F}$ Pediat 1992;121:634-40.

15 Manasco PK, Pescovitz OH, Blizzard RM. Local reactions to depot leuprolide therapy for central precocious puberty [letter]. F Pediatr 1993;123:334-5.

16 Tonini G, Marinoni S, Forleo V. Local reactions to luteinizing hormone releasing hormone analog therapy. $\mathcal{F}$ Pediatr 1995;126:150-60.

17 Nishio S, Morioka T, Fukui M, Goto Y. Surgical treatment of intractable seizure due to hypothalamic hamartoma. Epilepsia 1994;35:514-19.

18 Stewart L, Steinbok P, Daaboul J. Role of surgical resection in the treatment of hypothalamic hamartomas causing precocious puberty. Report of six cases. F. Neurosurg 1998;88: $340-5$.

\section{FETAL AND NEONATAL EDITION}

\section{March Issue}

The following articles-being published in the March 1999 issue of the Fetal and Neonatal edition of Archives of Disease in Childhood - may be of particular general interest as they relate to community, social, and neurodevelopmental paediatrics.

Visual function in term infants with hypoxic-ischaemic insults: correlation with neurodevelopment at 2 years of age

Eugenio Mercuri, Leena Haataja, Andrea Guzzetta, Shirley Anker, Frances Cowan, Mary Rutherford, Rachel Andrew, Oliver Braddick, Giovanni Cioni , Lilly Dubowitz, Fanette Atkinson

Survival and place of delivery following preterm birth: 1994-96

David Field, Elizabeth S Draper

Trends in incidence of cranial ultrasound lesions and cerebral palsy in very low birthweight infants 1982-93

Richard W I Cooke

Blood concentrations of pancreatitis associated protein in neonates: relevance to neonatal screening for cystic fibrosis

Facques Sarles, Sandrine Barthellémy, Claude Férec, Fuan Iovanna, Michel Roussey, fean-Pierre Farriaux, Annick Toutain, facques Berthelot, Nicole Maurin, fean-Pierre Codet, Patrice Berthézène, fean-Charles Dagorn

Prospective study of outcome in antenatally diagnosed renal pelvis dilatation Mervyn S fawson, Loraine Dibble, Sheila Puri, Facky Davis, fane Young, Raj Dave, Heulwen Morgan

Mortality from early onset group B streptococcal infection in the United Kingdom Nick Embleton, Unni Wariyar, Edmund Hey

Unlicensed and off label drug use in neonates

Sharon Conroy, Fohn McIntyre, Imit Choonara

"Sucrose analgesia": absorptive mechanism or taste perception? Luca A Ramenghi, David F Evans, Malcolm I Levene

BASIC SCIENCE

Plausible explanations for effects of long chain polyunsaturated fatty acids (LCPUFA) on neonates

L O Kurlak, T F Stephenson 